\title{
Analysis on causes of flash flood in Jeddah city (Kingdom of Saudi Arabia) of 2009 and 2011 using multi-sensor remote sensing data and GIS
}

\begin{abstract}
The Jeddah city is located in a coastal plain area, in the middle of the western side of the Kingdom of Saudi Arabia, bounded by the Red Sea to the west and mountains to the east. Jeddah city receives rainfall runoff from the foothills through different drainage pathways (wadis). During intense rainfall events, runoff flows westward from the hills and mountains towards the Red Sea, causing flash floods in the urban areas along the pathways of these wadis. Two major flash flood events occurred in Jeddah city during 20 November 2009 January 2011. These events were characterized by rainfall precipitation values of 70 and 111 $\mathrm{mm}$, respectively. Each flash flood event has duration of three hours. The impact of these two flood events have been disastrous causing extensive flooding that killed 113 people in 2009 and damaged infrastructure and property (more than 10,000 homes and 17,000 vehicles). This study deals with the analysis of the different factors that caused these flash flood events. The results indicate that the causes of these floods are related to a number of factors which play as a major contribution to the worsening of the flood disaster. These factors were classified into the following: geomorphological features, anthropogenic activities (urban changes), network and catchment factors, and rainfall and climatic changes factors. The climatic changes have a major impact on the rainfall intensity and will appear more in the future. Other factors related to the wadis tributaries are narrow passes, and high slope of the wadi has additional impacts in the flash floods in the area. The anthropogenic activities include the proliferation of slums and construction in the valleys coupled with the lack of suitable water streams to accommodate the amount of water flowing and the presence of dirt led to the direction of flow.
\end{abstract}

Keyword: Flash floods; Jeddah; Climatic changes; Anthropogenic activity; Rainfall intensity; Remote sensing data 